\title{
BMJ Global Health Over-the-counter antibiotic dispensing by pharmacies: a standardised patient study in Udupi district, India
}

\author{
Vaidehi Nafade, ${ }^{1,2}$ Sophie Huddart, ${ }^{1,2}$ Giorgia Sulis,, ${ }^{1,2}$ Amrita Daftary, ${ }^{3}$ \\ Sonal Sekhar Miraj, ${ }^{4,5}$ Kavitha Saravu (D) ,", Madhukar Pai (D) 1,2,5
}

To cite: Nafade V, Huddart S, Sulis G, et al. Over-the-counter antibiotic dispensing by pharmacies: a standardised patient study in Udupi district, India. BMJ Global Health 2019;4:e001869. doi:10.1136/ bmjgh-2019-001869

Handling editor Seye Abimbola

- Additional material is published online only. To view please visit the journal online (http://dx.doi.org/10.1136/ bmjgh-2019-001869).

Received 26 July 2019 Revised 28 September 2019 Accepted 5 October 2019

\section{Check for updates}

\section{Author(s) (or their} employer(s)) 2019. Re-use permitted under CC BY-NC. No commercial re-use. See rights and permissions. Published by BMJ.

For numbered affiliations see end of article.

Correspondence to Dr Kavitha Saravu; kavithasaravu@gmail.com

\section{ABSTRACT}

Background Antimicrobial resistance is a global health emergency, and one of the contributing factors is overuse and misuse of antibiotics. India is one of the world's largest consumers of antibiotics, and inappropriate use is potentially widespread. This study aimed to use standardised patients (SPs) to measure over-the-counter antibiotic dispensing in one region.

Methods Three adults from the local community in Udupi, India, were recruited and trained as SPs. Three conditions, in both adults and children, were considered: diarrhoea, upper respiratory tract infection and acute fever. Adult SPs were used as proxies for the paediatric cases.

Results A total of 1522 SP interactions were successfully completed from 279 pharmacies. The proportion of SP interactions resulting in the provision of an antibiotic was $4.34 \%(95 \% \mathrm{Cl} 3.04 \%$ to $6.08 \%)$ for adult SPs and $2.89 \%$ $(95 \% \mathrm{Cl} 1.8 \%$ to $4.4 \%)$ for child SPs. In the model, referral to another provider was associated with an OR 0.38 (95\% $\mathrm{Cl} 0.18$ to 0.79 ), the number of questions asked was associated with an OR 1.54 (95\% $\mathrm{Cl} 1.30$ to 1.84$)$ and an SP-pharmacist interaction lasting longer than $3 \mathrm{~min}$ was associated with an $\mathrm{OR} 3.03(95 \% \mathrm{Cl} 1.11$ to 8.27$)$ as compared with an interaction lasting less than $1 \mathrm{~min}$. Conclusion Over-the-counter antibiotic dispensing rate was low in Udupi district and substantially lower than previously published SP studies in other regions of India. Dispensing was lowest when pharmacies referred to a doctor, and higher when pharmacies asked more questions or spent more time with clients.

\section{INTRODUCTION}

Antimicrobial resistance is a global health emergency, and poor antimicrobial stewardship, which includes both overuse and misuse of these drugs, is a contributing factor. ${ }^{1}$ Estimates suggest that $20 \%-50 \%$ of global antibiotic use is inappropriate, ${ }^{2}$ but it is difficult to measure this in resource-constrained settings where surveillance is a challenge.

India is a leading consumer of antibiotics globally. Between 2000 and 2015, antibiotic consumption in India doubled, making India the highest-consuming low-income and middle-income country (LMIC). ${ }^{3}$ However,

\section{Key questions}

What is already known?

- The overuse and misuse of antibiotics is a contributing factor to antimicrobial resistance, and India consumes the most antibiotics of any country.

- Standardised patients (SPs) have been used to assess quality of care in India and other low-income and middle-income countries, and have shown that in India, private retail pharmacies are a source of non-prescription antibiotics.

- These studies have reported that up to $40 \%$ of pharmacies provide non-prescription antibiotics, but the most studies are limited to one or two medical conditions.

\section{What are the new findings?}

- In the district of Udupi, Karnataka, we completed 1522 pharmacy-SP interactions including three conditions in both adults and children- upper respiratory tract infection, diarrhoea and fever-and found that only $4 \%$ of pharmacies provided nonprescription antibiotics.

- Antibiotic dispensing was highest when pharmacies asked more questions or spent more time with the $\mathrm{SP}$, and lowest when they referred the SP to another provider.

- Despite the low rate of antibiotic dispensing, case management by pharmacies was still poor as evaluated by adherence to international guidelines, and varied greatly according to the condition presented and whether the SP was an adult or paediatric case.

What do the new findings imply?

- In some areas of India, non-prescription antibiotic dispensing by pharmacies may not be as prevalent as previously thought, although overall quality of care remains a problem.

- In addition to provider-level variation in antibiotic dispensing, geographical and demographic factors may be relevant, though further research is required.

India also has a high infectious disease burden, ${ }^{4}$ and a high burden of mortality due to drug-resistant pathogens. ${ }^{5}$ India has a highly privatised medical system with a large informal sector, and many patients access 
antibiotics over the counter (OTC) via over 750000 retail pharmacies across the country, ${ }^{6}$ and it has been documented that these pharmacies dispense antibiotics without a prescription.?

According to the Drugs and Cosmetics Rules Act from the Indian government, ${ }^{8}$ all antibiotics are designated as Schedule $\mathrm{H}$, which means that pharmacies cannot dispense them without a prescription. In 2013, in an effort to regulate use of certain antibiotics such as newer cephalosporins and fluoroquinolones, carbapenems and antituberculosis drugs, the Indian government introduced a second schedule, H1. Pharmacies must maintain a register of all Schedule H1 drugs dispensed, recording the name and quantity of the drug as well as patient details. ${ }^{9}$ A further schedule of drugs, schedule X, requires pharmacists to also keep the original prescription on hand for 2 years; this schedule includes restricted drugs such as narcotics and sedatives.

Thus, OTC antibiotic dispensing is technically illegal, but enforcement of these regulations is challenging. This is concerning as overall antibiotic consumption in countries has been linked to a higher prevalence of antibiotic resistance,${ }^{10}$ and the use of antibiotics in the individual is linked with the subsequent emergence of resistant bacteria in the body. ${ }^{11}$ Thus, the practice providing antibiotics without a diagnosis may unnecessarily promote resistance.

Where prescription audits are not possible, standardised (or simulated) patients (SPs) have been used to study pharmacy practices in India and other LMICs. ${ }^{12}$ The SP methodology is considered as the gold-standard method to assess provider practice. ${ }^{13} 14$ Specifically in India, this methodology has been successfully applied to provide insight on how pharmacists manage cases of tuberculosis ${ }^{15} 16$ or respiratory tract infection ${ }^{17}$ for adult patients and paediatric diarrhoea. ${ }^{16} 18$ These SP studies have found that $15 \%$ to upwards of $40 \%$ of SP visits involved the provision of a non-prescription antibiotic.

We report here the results of a cross-sectional SP study assessing OTC antibiotic dispensing in private pharmacies in the district of Udupi, located in Karnataka state, India. This study builds on previous SP studies by our team ${ }^{14}{ }^{15}$ by extending the number of case scenarios to three common conditions: upper respiratory tract infection (URI), diarrhoea and fever suggestive of malaria.

\section{METHODS \\ Objectives}

This study was conducted in the district of Udupi, Karnataka, in South India. The primary objective was to assess overall non-prescription, OTC antibiotic dispensing by private, community retail pharmacies for adults and children for URI, acute, uncomplicated diarrhoea and a fever suggestive of malaria. Secondary objectives were to examine how this outcome differed between adults and children, and to determine which factors of the SP visithistory taking by the pharmacy, client volume at the time of visit, whether the SP was referred to another provider, approximate time spent at the pharmacy and pharmacy location (urban or rural) -were associated with antibiotic dispensing.

\section{Standardised patients}

SPs are individuals recruited locally, trained to make identically scripted clinical presentations, deployed incognito to visit healthcare providers and debriefed using a structured reporting instrument. Table 1 summarises the three SP case scenarios. Treatment for each condition was benchmarked against available guidelines from WHO on the management of the common cold, ${ }^{19}$ diarrhoea $^{20}$ and suspected malaria ${ }^{21}$; antibiotics are not indicated in any case. The appendix includes a description of all guidelines referenced to determine ideal management for each case.

Three adults were recruited from the local community as SPs. For the paediatric scenarios, adults were used as proxy SPs-no children were recruited. The SPs were instructed to visit the pharmacy and first request medication for a sick 2-year-old child at home and then request medication for their own illness. Thus, two cases were presented in a visit; each was considered a separate SPpharmacy interaction.

\section{Selection of pharmacies and SP visits}

The district of Udupi has a population of approximately 1.2 million people, and, according to a list from the local pharmacists association, 350 private pharmacies were active at the time of the study. Ultimately, 279 pharmacies were included in our sample. Pharmacies were categorised as 'urban' or 'rural' according to census guidelines ${ }^{22}$; the sample included 155 rural pharmacies and 124 urban pharmacies. Between 23 July 18 and 6 October 2018, each SP was instructed to visit each pharmacy and present their respective adult and paediatric cases. Further information on sample size calculation and pharmacy selection is available in online supplementary table $\mathrm{S} 1$ in the online supplementary appendix.

SPs were instructed to purchase any medications provided and place them in labelled envelopes. SPs filled out a structured questionnaire describing the visit using the EpiCollect 5 software on their mobile phones within half an hour of the interaction. In the case of the fever scenario, SPs reported whether a malaria test was recommended. Medications were then identified and classified as Schedule $\mathrm{H}$ or $\mathrm{H} 1$ by a trained research assistant. An infectious disease physician (GS) identified, coded and classified all antibiotics.

The waiver was approved because informed consent posed a threat to the scientific validity of this study, as it would increase the risk of SP detection and providers may alter their behaviour if they are aware of observation. The study posed minimal to no risk to pharmacies and their staff, as all information was kept confidential and no personal information was collected. There was also 
Table 1 SP case scenarios for both adults and children, with expected management

\begin{tabular}{ll}
\hline $\begin{array}{l}\text { Description of the } \\
\text { case scenario }\end{array}$ & Symptoms \\
\hline $\begin{array}{l}\text { Upper respiratory } \\
\text { tract infection } \\
\text { (URI), likely of viral } \\
\text { aetiology }\end{array}$ & $\begin{array}{l}\text { Individual with a 2-day history } \\
\text { of acute-onset low-grade } \\
\text { fever, with runny nose and } \\
\text { non-productive cough; does } \\
\text { not look sick. Family members } \\
\text { have similar symptoms. }\end{array}$ \\
$\begin{array}{ll}\text { Uncomplicated, } \\
\text { acute diarrhoea }\end{array}$ & $\begin{array}{l}\text { Individual with 1-day history of } \\
\text { acute onset, watery diarrhoea; } \\
\text { no blood in the stool. No fever. } \\
\text { Appears well hydrated. }\end{array}$
\end{tabular}

Appears well hydrated.
Opening statement by the SP on entering the pharmacy

Child with URI: 'Sir/Ma'am, my niece at home has fever and cough. Can you give me some medicine for her?'

Adult with URI: 'Since two days I have cough and fever. Can you help me?'

Child with diarrhoea: 'Sir/Ma'am, my niece at home has diarrhoea. Can you give me some medicine for her?'

Adult with diarrhoea: 'I have diarrhoea. Can you help me?'

\section{Expected management}

Acceptable: Not dispensing antibiotics, with or without referral to a doctor; dispensing symptomatic treatments according to current guidelines. Unacceptable: Dispensing antibiotics and/or steroids.

Acceptable: Dispensing oral rehydration salts (ORS), not dispensing antibiotics, with or without referral to a doctor. For paediatric SPs, zinc should be given with ORS.

Unacceptable: Dispensing antibiotics and restricted antimotility drugs such as loperamide.

$\begin{array}{ll}\begin{array}{l}\text { Acute febrile illness } \\ \text { suggestive of }\end{array} & \begin{array}{l}\text { Individual with a 4-day history } \\ \text { of high fever with shivering/ } \\ \text { malaria }\end{array} \\ & \text { chills, every other day; no } \\ & \text { cough or any other symptoms. } \\ & \text { No headache, fits or altered } \\ & \text { consciousness. }\end{array}$

Child with fever: 'Sir/Ma'am, since four days my niece has fever and chills. Can you give me some medicine for him?'

Adult with fever: 'I have fever since a few days that is not going away. also get chills. minimal risk to individuals recruited as SPs as they were trained to avoid detection and examinations.

\section{Patient and public involvement}

This research was done without patient involvement, particularly as this was not a clinical study. SPs cases were developed in conjunction with physicians, not patients. Individuals hired as SPs were recruited from the local public and were invited to comment on the SP case design.

\section{Statistical analysis}

The main outcome considered was the proportion of SP-pharmacy interactions resulting in the provision of an antibiotic. Secondary outcomes were the proportion of all interactions with acceptable case management and the proportion of interactions resulting in the provision of any medication, a schedule $\mathrm{H}$ medication, a schedule H1 medication or other medications of clinical relevance to that case. The proportions were compared for adults and children using McNemar's test for paired proportions. The adult and paediatric cases were considered paired because a single SP would present both in one interaction.

To evaluate factors associated with antibiotic dispensing, we fit a model using generalised estimating equations with a logit link to account for clustering by pharmacy. Adult and paediatric interactions were pooled for this analysis. To examine how antibiotic dispensing practices for adults and children were correlated, we fit a second logistic generalised estimating equation with antibiotic dispensing for the paediatric SP-pharmacy interactions as the outcome. The covariate of interest was whether an antibiotic was dispensed for the corresponding adult interaction, that is, the adult SP with the same condition at the same pharmacy. All analyses were adjusted for the case presented (both condition and whether the patient was adult or paediatric). Individual SP fixed effects were not included because each case was always presented by the same person. Theoretically, it is possible that SP characteristics, such as sex, age, height or weight, could affect pharmacists' behaviour. However, as each SP case scenario was only portrayed by one individual in this study, any potential variation here will be accounted for with the case fixed effect, and SP characteristics were never included as an additional covariate in the models. A full description of the variables included, as well as the choice of model and alternate analysis, is available in the online supplementary appendix table S2, figure $\mathrm{S} 1$, figure S2, figure S3.

Data were collected using EpiCollect 5 and Excel (V.1901) and analysed using R (V.3.4.1).

\section{RESULTS}

Of the 837 planned visits to 279 pharmacies, 761 (91\%) were successfully completed, resulting in a total of 1522 interactions including both adult and child cases. The 
average cost per visit was 38 Indian rupees (IQR: INR15INR50) (US\$0.22-US\$0.72), with a maximum cost of 158 rupees (US\$2.28). Of the 761 visits, there were no customers other than the SP present for 440 (58\%). Visits were relatively short; 601 (79\%) lasted less than $1 \mathrm{~min}$. Pharmacy staff asked an average of 1.18 questions and dispensed an average of 0.79 drugs per interaction. In total, 1218 medications were dispensed, of which 22 $(1.8 \%)$ could not be identified because the tablet strip had been cut. No loose pills were dispensed. To our knowledge, SPs were not detected, and no pharmacy staff attempted to perform any examinations on-site nor give any injections.

\section{History taking}

Adults were asked a mean of $1.04(\mathrm{SD} \pm 0.87)$ and a median of 1.0 questions, and paediatric cases elicited a mean of 1.31 ( $\mathrm{SD} \pm 0.82$ ) and a median of 1.0 questions.

History taking was highly variable according to case. Across all interactions, $86.5 \%(95 \%$ CI $84.7 \%$ to $88.2 \%$ ) of pharmacies asked at least one question. This percentage was $74.6 \%$ (95\% CI $71.3 \%$ to $77.6 \%$ ) for adult scenarios and $98.4 \%$ (95\% CI $97.2 \%$ to $99.1 \%$ ) for paediatric scenarios. Across all paediatric scenarios, the most commonly asked question was age $(97.9 \%$ of 761 interactions, $95 \%$ CI $96.5 \%$ to $98.8 \%$ ), and only $22.4 \%$ (95\% CI $19.5 \%$ to $25.5 \%$ ) of pharmacies asked some recommended question other than age. Overall, adult SPs were asked significantly more recommended questions than paediatric SPs. Online supplementary table S3 in the supplementary appendix lists all recommended questions and how often they were asked.

\section{Case management and medications dispensed}

Table 2 shows the number and percentage of interactions for the primary and secondary outcomes and case management, overall and separated by SP case. The proportion of SP interactions resulting in the provision of any medication was $87.2 \%$ (95\% CI $84.5 \%$ to $89.4 \%$ ) for adult SPs and $55.5 \%$ (95\% CI $51.9 \%$ to $59 \%$ ) for child SPs. Antibiotics were provided in 33 adult interactions (4.34\% of 761 interactions, $95 \%$ CI $3.04 \%$ to $6.08 \%$ ) and 22 paediatric interactions $(2.89 \%$ of 761 interactions, $95 \%$ CI $1.86 \%$ to $4.4 \%$ ). A $2 \times 2$ table for overall antibiotic dispensing to adult and paediatric SPs is included in online supplementary table S4 of the online supplementary appendix.

Case management, including medication dispensing for adults versus children, is illustrated in figure 1. Case management was worst for the diarrhoea condition, with not a single pharmacy managing this case correctly. This is because ORS were never offered to adults, and while ORS were provided in $13.4 \%$ (95\% CI $9.61 \%$ to $18.4 \%$ ) of paediatric diarrhoea interactions, zinc was never dispensed. Fever was only managed correctly for $1.19 \%$ (95\% CI $0.31 \%$ to $3.73 \%)$ of adult SPs and $3.86 \%(95 \%$ CI $1.97 \%$ to $7.2 \%$ ) of child SPs as these were the only interactions where the SP was referred for a malaria test.

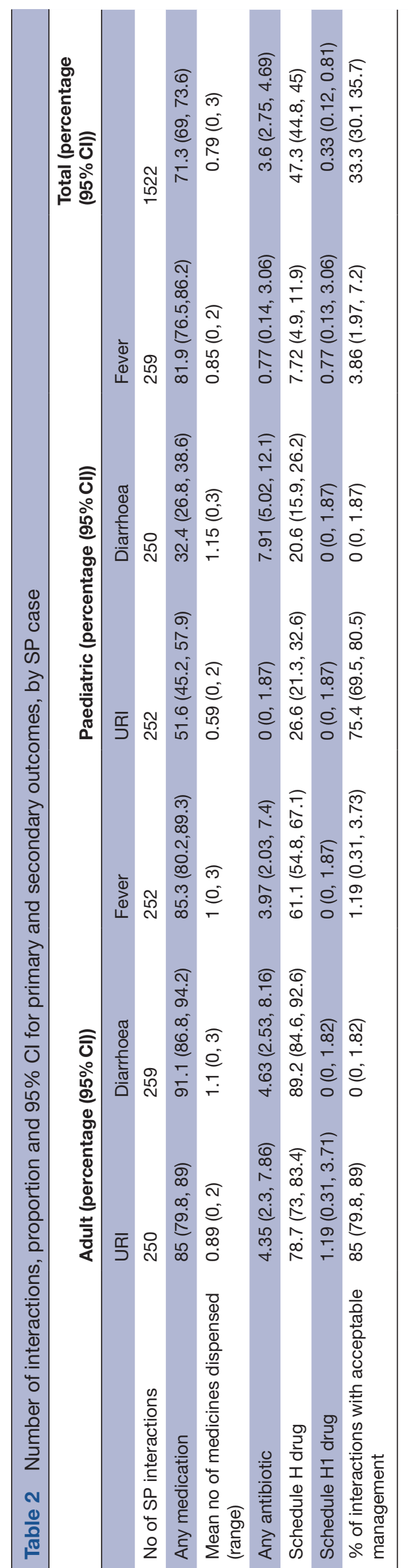


URI

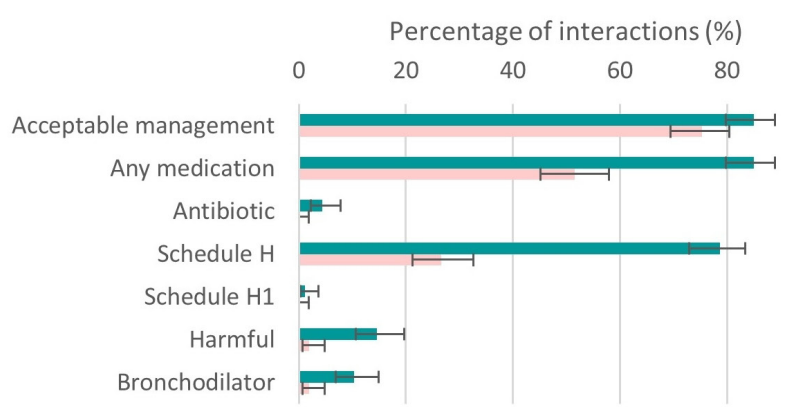

Diarrhoea

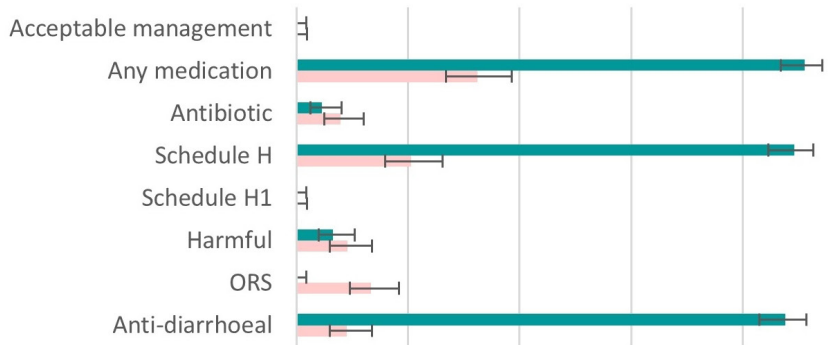

Fever

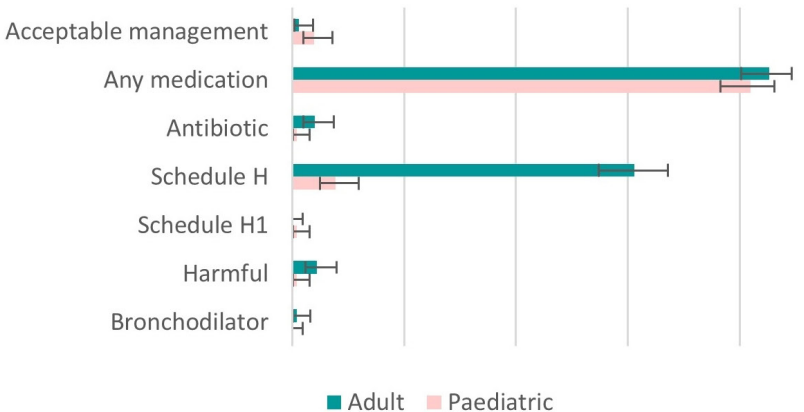

Figure 1 Management of SP cases, by condition, for adults and children. Error bars indicate 95\% Cl. SP, standardised patient; URI, upper respiratory tract infection.

Of all interactions, $71.6 \%$ (95\% CI $69 \%$ to $73.6 \%$ ) resulted in the provision of some medication. All medications provided are listed in figure 2, by active drug ingredient and separated by SP case scenario. Nearly half of SPs received schedule $\mathrm{H}$ medications, and a list of all non-antibiotic schedule $\mathrm{H}$ drugs provided can be found in online supplementary table S5 of the supplementary material. No schedule X medications were dispensed, and only five interactions resulted in the provision of a schedule $\mathrm{H} 1$ medication; all five were the antibiotic cefixime. The most common medications were paracetamol, loperamide for the diarrhoea, and cough and cold remedies including antihistamines and bronchodilators for the URI and fever conditions.

Of the 1218 medications provided, 55 (4.5\%) were products containing antibiotics. Of these, 25 were combinations of two antibiotics. Overall, diarrhoea was the condition resulting in the most antibiotic dispensing, accounting for $36.3 \%$ (95\% CI $21 \%$ to $54.9 \%$ ) of antibiotics given to adults and $90.9 \%$ (95\% CI $69.4 \%$ to $98.4 \%$ ) among children. As antibiotics were not indicated for any SP case by design, all antibiotic provision in this study was deemed inappropriate.

\section{Factors associated with antibiotic dispensing}

The results of the pooled model are displayed in table 3 . A number of customers present at the time of the interaction and whether the pharmacy was urban or rural were both non-significant. Referral to another provider was associated with an OR 0.38 (95\% CI 0.18 to 0.79 ), indicating that pharmacy staff referring the SP to another provider was associated with lower odds of dispensing antibiotics. Increasing number of questions asked was associated with an OR 1.54 (95\% CI 1.30 to 1.84), indicating that as pharmacy staff asked more questions, the odds of dispensing an antibiotic increased. Finally, an SP-pharmacist interaction lasting longer than $3 \mathrm{~min}$ was associated with an OR 3.03 (95\% CI 1.11 to 8.27); compared with an interaction lasting less than $1 \mathrm{~min}$, an interaction of this length was associated with increased odds of antibiotic dispensing. The OR for interactions lasting 1-3 min, as compared with those lasting less than $1 \mathrm{~min}$, was non-significant.

\section{Relationships between adult and paediatric outcomes}

The difference between the proportion of adults (4.3\%) and children $(2.9 \%)$ SP interactions resulting in an antibiotic was non-significant $(\mathrm{p}=0.1)$. However, adults received significantly more medications overall $(87.4 \%$ of adult interactions vs $55.7 \%$ of child interactions) and significantly more schedule $\mathrm{H}$ medications $(76.7 \%$ of interactions vs $18.3 \%$ ), with $\mathrm{p}<0.001$ for both.

To further investigate how adult and paediatric outcomes were related, we fit a second model to see if the treatment of the adult predicted the treatment of the child. For this analysis, only the diarrhoea condition was considered, as very few antibiotics were dispensed for the other two conditions and the model was not adequately powered for that rate of dispensing. The results of the model are shown in table 4. Dispensing of antibiotics for the corresponding adult SP interaction was associated with an OR 6.34 (95\% CI.69 to 23.82) for paediatric dispensing.

\section{DISCUSSION}

To our knowledge, this is the first SP study to examine OTC antibiotic dispensing by pharmacies in the Indian private sector for multiple medical conditions, in both adults and children (by proxy). Antibiotics were provided without a prescription and when they were not indicated, along with other schedule $\mathrm{H}$ medications. Overall, antibiotics were dispensed in $4.34 \%$ of adult interactions and $2.89 \%$ of paediatric interactions, and diarrhoea was the condition resulting in the most dispensing. Adults received significantly more medications overall, but the 
URI

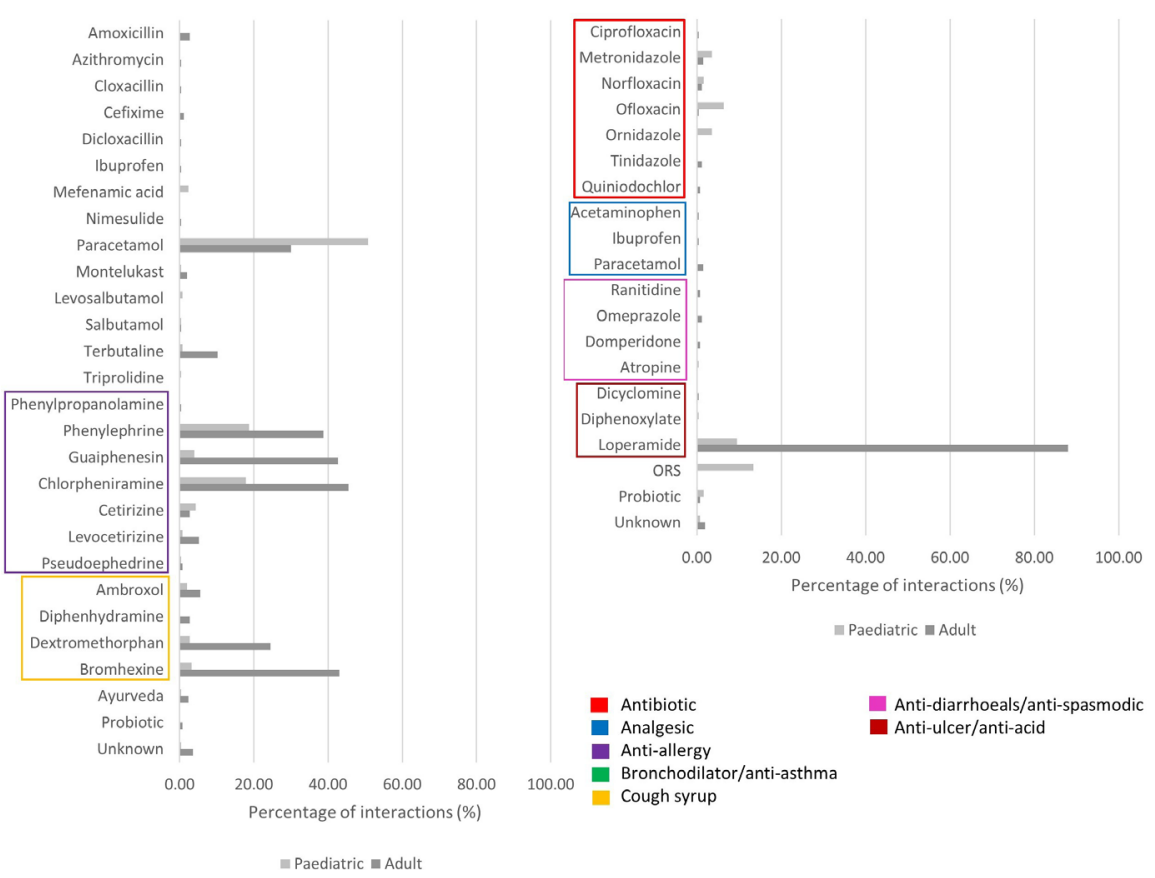

Fever

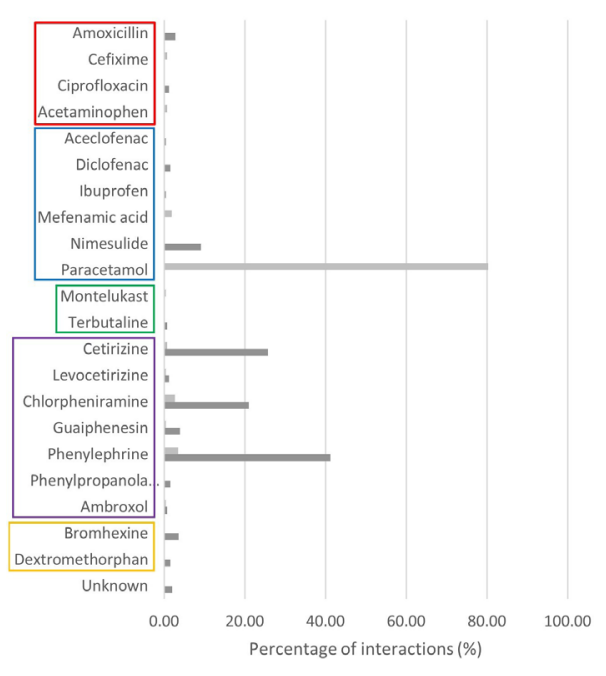

$m$ Paediatric $m$ Adult

Figure 2 Active drug ingredients in medications provided to SPs by SP case, for adults and children. Percentages do not sum to $100 \%$ as one medication may have contained more than one active drug ingredient. SPs, standardised patients; URI, upper respiratory tract infection.

difference in the proportion of interactions resulting in the provision of an antibiotic was not statistically significant between adults and children.

Our results also provide moderate evidence that adult and child outcomes are correlated. For the case of paediatric diarrhoea, whether the adult SP with diarrhoea received an antibiotic was a significant predictor, suggesting that pharmacies that provided adults with antibiotics were more likely to do the same for children. This finding may in part be due to the study design, where one adult presented two cases in one visit. However, the adult SP never presented the same condition twice in one visit, and our model adjusts for correlation in outcomes at the pharmacy level.

Given the results of previous SP studies ${ }^{15-18}$ and qualitative data demonstrating that retail pharmacists are willing to provide antibiotics for common ailments, ${ }^{23}$ it is not surprising that antibiotics were dispensed. The rate of antibiotic dispensing in our study, however, is lower than that seen in other Indian studies; for example, two previous SP studies reported that over $30 \%$ of pharmacies provided antibiotics for paediatric diarrhoea. ${ }^{16}$

Regions within India are not only culturally different, but vary in their degree of development, enforcement of regulations and awareness about antimicrobial stewardship. It is, thus, plausible that pharmacy practice varies geographically, and this has been observed. A study conducted by Satyanarayana $e t$ al in pharmacies in Patna and Mumbai, two major cities located in different states, found that approximately $15 \%$ of interactions in Mumbai resulted in the provision of an antibiotic, compared with approximately $39 \%$ in Patna. ${ }^{15}$
The district of Udupi, where our study was conducted, is well developed. The literacy rate is $86.24 \%, 10 \%$ above the state average. ${ }^{24}$ In 2014, Udupi had the third greatest per capita income in the state, and less than $1 \%$ of the population lived in slums. ${ }^{25}$ The district also performs well on many health indicators: the percentage of deliveries that are institutional births is $19 \%$ above the national average and the prevalence of stunting in children under age five is $17 \%$ lower than the national average. ${ }^{26}$ This may reflect better healthcare coverage and access to doctors, in which case pharmacists may not be motivated to step into the role of a de facto medical care provider. As studies have only included one or two cities, further research would be required to determine if, and to what extent, demographic and geographical characteristics affect OTC antibiotic dispensing.

History taking and case management varied according to case, and management was particularly poor for fever and diarrhoea. Improved history taking did not necessarily result in better case management, as $100 \%$ of adults were asked at least one question for the fever condition but only $1 \%$ were referred for a malaria test. Further, bronchodilators and antiallergy medications were frequently provided for this condition (online supplementary figure 2, table S5), although the SP presentation did not involve symptoms of respiratory illness. The poor case management for fever is concerning, as a study in the city of Mangaluru, a district adjacent to our study site, found that over $30 \%$ of surveyed patients with a malaria diagnosis first visited a pharmacy. ${ }^{27}$

In contrast to diarrhoea and fever, the rate of correct case management for URI was over $80 \%$ for both adults 


\begin{tabular}{|c|c|c|}
\hline & $\mathrm{OR}^{*}(95 \% \mathrm{Cl})$ & $P$ value \\
\hline \multicolumn{3}{|l|}{ History taking } \\
\hline No of questions asked & $1.54(1.30,1.84)$ & 0.00009 \\
\hline \multicolumn{3}{|l|}{ Pharmacy location } \\
\hline Urban pharmacy & Reference & \\
\hline Rural pharmacy & $0.94(0.52,1.68)$ & 0.82 \\
\hline \multicolumn{3}{|l|}{ Referral } \\
\hline Patient not referred & Reference & \\
\hline $\begin{array}{l}\text { Patient referred to another } \\
\text { provider }\end{array}$ & $0.38(0.18,0.79)$ & 0.0035 \\
\hline \multicolumn{3}{|l|}{ Client volume at the pharmacy } \\
\hline No of customers present & Reference & \\
\hline One to three customers & $0.97(0.48,1.97)$ & 0.93 \\
\hline More than three customers & $1.18(0.39,3.59)$ & 0.78 \\
\hline \multicolumn{3}{|l|}{ Length of interaction } \\
\hline Less than $1 \mathrm{~min}$ & Reference & \\
\hline $1-3 \mathrm{~min}$ & $0.93(0.41,2.08)$ & 0.85 \\
\hline More than $3 \mathrm{~min}$ & $3.03(1.11,8.27)$ & 0.03 \\
\hline \multicolumn{3}{|l|}{ Case } \\
\hline URI & Reference & \\
\hline Diarrhoea & $2.83(1.47,5.45)$ & 0.0046 \\
\hline Fever & $0.83(0.37,1.83)$ & 0.66 \\
\hline \multicolumn{3}{|l|}{ Patient age } \\
\hline Child & Reference & \\
\hline Adult & $1.65(0.92,2.96)$ & 0.099 \\
\hline
\end{tabular}

ORs are for the outcome of antibiotic dispensing by the pharmacy. ${ }^{*}$ All ORs are adjusted for case and age of SP (adult/child). URI, upper respiratory tract infection.

and children, although only $28 \%$ of children were asked a recommended question. This level of questioning would not be enough to differentiate a common cold from a serious condition such as pneumonia. Additionally, schedule $\mathrm{H}$ medications were still widely dispensed. The provision of unnecessary medications is concerning not only from a medical standpoint; it also reflects unnecessary financial costs to the individual patient. This is particularly unfortunate given that Indians with low income commonly rely on pharmacists, partly to save costs associated with visiting private providers.$^{28}$ However, it is encouraging that very few schedule $\mathrm{H} 1$, and no schedule X, medications were dispensed.

Pharmacist knowledge is also a factor in pharmacists' behaviour and antibiotic dispensing. ${ }^{729}$ Knowledge was not specifically evaluated in our study, but referral, a potential indicator of better practice, was associated with lower provision of antibiotics. However, history taking had the opposite effect: as pharmacists asked more questions, the odds of dispensing increased. This is unexpected as the scripted responses to questions were designed to rule out the possibility of severe illness and discourage the provision of antibiotics. A possible explanation for
Table 4 Results of model fit using generalised estimating equations with a logit link with antibiotics dispensed for paediatric SPs with diarrhoea as the outcome $(n=233)$

\begin{tabular}{|c|c|c|}
\hline & OR (95\% Cl) & $P$ value \\
\hline \multicolumn{3}{|l|}{ History taking } \\
\hline No of questions asked & $1.34(0.94,1.93)$ & 0.29 \\
\hline \multicolumn{3}{|l|}{ Pharmacy location } \\
\hline Urban pharmacy & Reference & \\
\hline Rural pharmacy & $2.54(0.90,7.20)$ & 0.11 \\
\hline \multicolumn{3}{|l|}{ Referral } \\
\hline Patient not referred & Reference & \\
\hline $\begin{array}{l}\text { Patient referred to another } \\
\text { provider }\end{array}$ & $0.07(0.02,0.25)$ & 0.00002 \\
\hline \multicolumn{3}{|l|}{ Client volume at the pharmacy } \\
\hline No customers present & Reference & \\
\hline Customers present & $1.23(0.41,3.70)$ & 0.98 \\
\hline \multicolumn{3}{|l|}{ Length of interaction } \\
\hline Less than $1 \mathrm{~min}$ & Reference & \\
\hline $1-3 \mathrm{~min}$ & $1.37(0.42,4.48)$ & 0.25 \\
\hline \multicolumn{3}{|l|}{ Antibiotic dispensed for adult } \\
\hline Not dispensed & Reference & \\
\hline Dispensed & $6.34(1.69,23.82)$ & 0.0062 \\
\hline
\end{tabular}

'Antibiotic dispensed for adult' refers to dispensing for an adult SP with the same condition at the same pharmacy. SPs, standardised patients.

this could be a situation of reverse causality: it is possible that pharmacy staff first decided to dispense antibiotics and then asked more questions, perhaps to identify the type of antibiotic or dosing, or to justify provision of the medication.

We also included the length of the SP-pharmacy interaction in our model. We found that particularly long interactions had greater odds of antibiotic dispensing. This is also unexpected; similar to history taking, it is plausible that pharmacy staff who spend more time with an SP would identify that the SP's symptoms are not severe and do not warrant the use of antibiotics. However, the number of questions asked was not highly correlated with length of interaction, indicating that long interactions were not because of increased history taking. This may indicate that the decision to dispense antibiotics is not only motivated by a perception of the drug's necessity. Patient demand-real or perceived-and financial incentives likely drive pharmacies to provide antibiotics even when they do not suspect bacterial illness, because retail pharmacies are primarily driven by business. ${ }^{29}$

Some strengths of our study are worth mentioning. Using SPs is an ideal method for studying OTC antibiotic dispensing, as it measures actual pharmacy practice rather than what they know (ie, knowledge) or say they would do (ie, self-reported practices). Standardising cases across individuals ensures that specific patient characteristics are unlikely to influence provider behaviour. Our study had a limited risk of poor recall, as few questions 
were asked and SPs filled out a questionnaire soon after their pharmacy visit. We build on the results generated from previous SP studies by extending the number of medical conditions assessed and by providing a comparison between adults and children. We additionally report how factors of the SP visit affect dispensing to better understand sources of variation. Lastly, our study covered $80 \%$ of registered pharmacies in the district. To our knowledge, no unregistered drug shops exist in Udupi district, though such informal sellers are known to exist in South Asia. ${ }^{7}$

However, this study has some limitations. It was conducted at a single site, meaning that the results are not generalisable to the rest of the country or even the state, and the SP study design does not allow us to determine why fewer antibiotics were dispensed in this setting. Additional qualitative and ethnographical research is required. Second, only male SPs were used in this study, and it is possible that patient gender affects provider practice. However, our choice was motivated by safety considerations, as some pharmacies were located in isolated areas and all SPs were unaccompanied. Third, our study was based on a single SP visit from an individual that has not visited the pharmacy before, so we cannot evaluate the effect of an existing relationship with a patient. We also cannot be sure that the staff member the SP interacted with was the pharmacist; a review of community pharmacy practice in India found that medications were often sold by non-qualified employees. ${ }^{30}$ Although our study captures the real experience of individuals visiting a pharmacy in the district, dispensing by untrained staff poses a problem for the development of antimicrobial stewardship programme, as training pharmacists alone may not be sufficient. A further limitation is that we were not able to analyse the financial burden of unnecessary antibiotic dispensing: though we collected data on the amount of money spent by each SP, receipts were never provided by pharmacies, so it is unclear how much was spent for the paediatric case versus the adult case. Also, a single adult SP presented both an adult and a paediatric case in the same interaction; this has been done before, ${ }^{16}$ and we do not believe that this would have a significant effect, particularly as all cases involved common symptoms. However, we cannot rule out the possibility that the results would be slightly different if the cases were presented separately.

\section{CONCLUSION}

Non-prescription antibiotic dispensing by pharmacies in Udupi was low, although prescription-only medications were frequently provided. However, even when antibiotics were not dispensed, case management was poor, with a lack of adequate history taking and referrals, and the dispensing of other unnecessary medications. Both dispensing and case management varies according to symptoms and the age of the patient. Additional research is required to understand the low rates of antibiotic dispensing by pharmacies in this area and use the knowledge to inform antibiotic stewardship interventions.

\section{Author affiliations}

1Department of Epidemiology, Biostatistics and Occupational Health, McGill University, Montreal, Québec, Canada

${ }^{2}$ McGill International Tuberculosis Center, McGill University, Montreal, Québec, Canada

${ }^{3}$ Faculty of Health, York university, Toronto, Ontario, Canada

${ }^{4}$ Department of Pharmacy Parctice, Manipal College of Pharmaceutical Sciences, Manipal Academy of Higher Education, Manipal, India

${ }^{5}$ Manipal McGill Program for Infectious Diseases, Manipal Center for Infectious Diseases, Prasanna School of Public Health, Manipal Academy of Higher Education, Manipal, Udupi, India

${ }^{6}$ Department of Infectious Diseases, Kasturba Medical College and Hospital, Manipal Academy of Higher Education, Manipal, India

Twitter Vaidehi Nafade @vnafade, Sophie Huddart @SKHuddart, Giorgia Sulis @giorgiasulis, Amrita Daftary @DaftaryAmrita, Kavitha Saravu @KavithaSaravu and Madhukar Pai @paimadhu

Acknowledgements This study was supported by a TMA Pai Endowment award from the Manipal Academy of Higher Education. The authors are grateful to Ada Kwan, Ben Daniels, Rosalind Miller and Sumanth Gandra for their input on the analysis, interpretation and manuscript; Rajan Singh and Charu Nanda from the Institute for Socioeconomic Research on Development and Democracy for their guidance and practical support in training the SPs and piloting the study; the SPs and local field staff; and the Manipal Centre for Infectious Disease for administrative support.

Contributors The study was designed by MP, KS and VN. The SP case scenarios and field visit plan were developed by MP, KS, VN and SSM. VN and KS supervised SP training, field visits and data collection. VN and GS coded the data, and VN and $\mathrm{SH}$ analysed the data. The data were interpreted by VN, GS, AD, KS and MP. The report was written by VN, MP and KS, and all authors provided review and comments.

Funding The study was funded by a TMA Pai Endowment Chair at the Manipal Academy of Higher Education, Manipal.

Disclaimer The funding source was not involved in the study design, data collection or analysis or data interpretation and manuscript writing.

Competing interests None declared.

Patient consent for publication Not required.

Ethics approval Approval for the study was obtained from the ethics committees of the Manipal Academy of Higher Education in Manipal, India, and McGill University in Montreal, Canada.

Provenance and peer review Not commissioned; externally peer reviewed.

Data availability statement Data are available on reasonable request.

Open access This is an open access article distributed in accordance with the Creative Commons Attribution Non Commercial (CC BY-NC 4.0) license, which permits others to distribute, remix, adapt, build upon this work non-commercially, and license their derivative works on different terms, provided the original work is properly cited, appropriate credit is given, any changes made indicated, and the use is non-commercial. See: http://creativecommons.org/licenses/by-nc/4.0/.

\section{ORCID iDs}

Kavitha Saravu http://orcid.org/0000-0001-6399-1129

Madhukar Pai http://orcid.org/0000-0003-3667-4536

\section{REFERENCES}

1 World Health Organization. Global Action Plan on Antimicrobial Resistance. Geneva: WHO, 2015.

2 World Health Organization. The World Medicines Situation: 2011. Geneva: WHO, 2011.

3 Klein EY, Van Boeckel TP, Martinez EM, et al. Global increase and geographic convergence in antibiotic consumption between 2000 and 2015. Proc Natl Acad Sci U S A 2018;115:E3463-70.

4 India State-Level disease burden initiative C. nations within a nation: variations in epidemiological transition across the states 
of India, 1990-2016 in the global burden of disease study. Lancet 2017;390:2437-60.

5 Gandra S, Tseng KK, Laxminarayan R, et al. The mortality burden of multidrug-resistant pathogens in India: a retrospective observational study. 2018.

6 All India Organisation of Chemists \& Druggists. All India Organisation of Chemists \& Druggists history, 2018. Available: http://www.aiocd. net/ [Accessed September 15 2018].

7 Goodman C, Miller R. Performance of retail pharmacies in low- and middle-income Asian settings: a systematic review. Health Policy Plan 2016;31:940-53.

8 Ministry of Health and Family Welfare Government of India. The drugs and cosmetics rules, 1945, 2013. Available: https://mohfw. gov.in/sites/default/files/638332522.pdf [Accessed January 4 2019].

9 Government of India Ministry of Health and Family Welfare. Notification G.S.R. 588(E). Health Do, ed. New Delhi: The Gazette of India Extraordinary, 2013.

10 Bell BG, Schellevis F, Stobberingh E, et al. A systematic review and meta-analysis of the effects of antibiotic consumption on antibiotic resistance. BMC Infect Dis 2014;14:13.

11 Costelloe C, Metcalfe C, Lovering A, et al. Effect of antibiotic prescribing in primary care on antimicrobial resistance in individual patients: systematic review and meta-analysis. BMJ 2010;340:c2096.

12 Watson MC, Norris P, Granas AG. A systematic review of the use of simulated patients and pharmacy practice research. Int $J$ Pharm Pract 2006;14:83-93.

13 Rethans J-J, Gorter S, Bokken L, et al. Unannounced standardised patients in real practice: a systematic literature review. Med Educ 2007:41:537-49.

14 Das J, Kwan A, Daniels B, et al. Use of standardised patients to assess quality of tuberculosis care: a pilot, cross-sectional study. Lancet Infect Dis 2015;15:1305-13.

15 Satyanarayana S, Kwan A, Daniels B, et al. Use of standardised patients to assess antibiotic dispensing for tuberculosis by pharmacies in urban India: a cross-sectional study. Lancet Infect Dis 2016;16:1261-8.

16 Miller R, Goodman C. Do chain pharmacies perform better than independent pharmacies? Evidence from a standardised patient study of the management of childhood diarrhoea and suspected tuberculosis in urban India. BMJ Glob Health 2017;2.
17 Shet A, Sundaresan S, Forsberg BC. Pharmacy-based dispensing of antimicrobial agents without prescription in India: appropriateness and cost burden in the private sector. Antimicrob Resist Infect Control 2015;4:55

18 Diwan V, Sabde YD, Byström E, et al. Treatment of pediatric diarrhea: a simulated client study at private pharmacies of Ujjain, Madhya Pradesh, India. J Infect Dev Ctries 2015;9:505-11.

19 World Health Organization. Cough and cold remedies for the treatment of acute respiratory infections in young children. Geneva: WHO, 2001.

20 World Health Organization. The treatment of diarrhoea: a manual for physicians and other senior health workers. Geneva: WHO, 2005.

21 World health Organization. Guidelines for the treatment of malaria. 3rd ed. Geneva: WHO, 2015.

22 Directorate of Census Operations. Census of India 2011, district census Handbook Udupi, 2011. Available: http://censusindia.gov. in/2011census/dchb/2915_PART_B_DCHB_UDUPI.pdf [Accessed January 4 2019].

23 Kotwani A, Wattal C, Joshi PC, et al. Irrational use of antibiotics and role of the pharmacist: an insight from a qualitative study in New Delhi, India. J Clin Pharm Ther 2012;37:308-12.

24 Census Population. Population census 2011, 2011. Available: https://www.census2011.co.in/[Accessed March 11 2019].

25 Department of Planning Programme Monitoring \& Statistics. Economic survey of Karnataka - 2015-2016, 2016. Available: http:// des.kar.nic.in/docs/Economic\%20Survey\%202015-16 English\% 20Final.pdf [Accessed March 11 2019].

26 International Institute for Population Sciences. National family health survey 4, 2016. Available: http://rchiips.org/nfhs/about.shtml [Accessed March 11 2019].

27 Dayanand KK, Punnath K, Chandrashekar V, et al. Malaria prevalence in Mangaluru City area in the southwestern coastal region of India. Malar J 2017;16:492.

28 Barker AK, Brown K, Ahsan M, et al. Social determinants of antibiotic misuse: a qualitative study of community members in Haryana, India. BMC Public Health 2017;17.

29 Radyowijati A, Haak H. Improving antibiotic use in low-income countries: an overview of evidence on determinants. Soc Sci Med 2003;57:733-44.

30 Basak SC, Mil JWF, Sathyanarayana D. The changing roles of pharmacists in community pharmacies: perception of reality in India. Pharm World Sci 2009;31:612-8. 